\title{
CONTRADIÇÕES NA DIVULGAÇÃO DE CONHECIMENTO CIENTÍFICO E CULTURAL
}

\author{
Solange Leda Gallo*
}

Resumo: Aqui fazemos uma reflexão sobre o trabalho que vem sendo desenvolvido há alguns anos no âmbito de um dos grupos de pesquisa inscrito na linha de pesquisa de "Texto e Discurso" do Programa de Pós-Graduação em Ciências da Linguagem da Unisul. Esse trabalho se materializa em várias publicações científicas de todo grupo e em duas producões digitais de divulgação de conbecimento, a Revista "Ciência em Curso" (www.cienciaemcurso.unisul.br) e o Projeto "feito a mão" (wnw.feitoamao.unisul.br). Discutimos aqui as contradições que estão na base da produção de conbecimento e de suas formas de circulação de acordo com resultados de análises já desenvolvidas. Essas análises recortam a questão da mediação no jornalismo científico e na divulgação científica, a questão do conhecimento científico e do conbecimento cultural, a questão da ciência em relação à C\& $T$; e a questão do discurso da contemporaneidade e da memória.

Palavras-chave: Análise de discurso. Divulgação de conhecimento científico e cultural. Contradição. Memória.

\section{INTRODUÇÃO}

Temos trabalhado com a divulgação de ciência a partir do grupo de pesquisa "Produção e circulação do conhecimento". ${ }^{1}$ Nesse âmbito, tomamos a divulgação científica como uma instância discursiva diferente do jornalismo científico (JC):

[...] o jornalismo científico tem, imaginariamente, como função, colocar em linguagem acessível os fatos/pesquisas científicas, os quais são herméticos e incompreensíveis para os sujeitos não especialistas. Nesse funcionamento do JC, a ciência é ressignificada a partir da sua "publicização", ou seja, a ciência é "retirada" do seu meio de circulação tradicional e levada a ocupar

\footnotetext{
* Docente e vice-coordenadora do Programa de Pós-Graduação em Ciências da Linguagem da Universidade do Sul de Santa Catarina - UNISUL. Doutora em Linguística pela Universidade Estadual de Campinas - UNICAMP. E-mail: solange.gallo@unisul.br.

${ }^{1}$ O Grupo, registrado no CNPq desde 2003 e por mim coordenado, faz parte do Programa de PósGraduação em Ciências da Linguagem da Unisul e abriga várias instâncias de pesquisa. Temos trabalhado com alunos de iniciação científica dos cursos de Comunicação Social e de Cinema e Realização Audiovisual, bem como alunos dos cursos de Mestrado e de Doutorado do Programa. As pesquisas que fazemos estão relacionadas tanto com conteúdos de produção de textos que se inscrevem no discurso de divulgação de conhecimento, como aqueles que se relacionam com a área de Análise de Discurso, tendo gerado nesse âmbito um vasto material.
} 
um lugar no "cotidiano" do grande público. O efeito de sentido que aí se estabelece é o que se pode chamar de "efeito de informação científica" (ORLANDI, 2001), em que o "conhecimento" científico passa a "informação" científica [...] (GALLO; MARTINS, 2010, p. 134)

De acordo com essa perspectiva comunicacional, portanto, a ciência é tomada como um dizer passível de "tradução" para um leitor leigo, que será "informado" sobre "fatos" relativos à produção científica, sem que isso se constitua para ele como conhecimento científico, uma vez que as condições de produção da ciência ficam apagadas pelo dizer sobre ciência.

Da perspectiva discursiva que adotamos, no entanto, o jornalismo, a ciência e a própria divulgação são considerados discursos e são constituídos, cada um deles, por suas condicões de produção (históricas, políticas, ideológicas) e por seus sujeitos. Considera-se, portanto, o cientista/especialista, o não especialista (sujeito leitor dos materiais de divulgação de ciência) e o próprio divulgador, sujeitos que ocupam uma posição necessariamente determinada por um contexto histórico e social, ou seja, constituídos por e em um discurso. (GALLO; MARTINS, 2010, p. 135)

\section{A CONTRADIÇÃO FUNDAMENTAL}

Para a Análise do Discurso, a noção de mediação à qual o jornalismo científico se propõe "traduzindo" um dizer em outro, traz uma contradição, ou seja, mediar, na perspectiva discursiva, significa passar de uma forma material (social, histórica e ideológoca) para outra forma material. Esse trabalho impossibilita a manutenção de um mesmo sentido, já que são as condiçõs históricas, sociais e ideológicas que determinam o sentido dos textos. Fazer tal transposição sem mobilizar a materialidade do discurso seria impossível, para nossos parâmetros. 
Assim, se o discurso científico tem sua materialidade própria e um modo de funcionamento que lhe é próprio, o discurso jornalístico também o tem, e são outros, bem diversos.

Então, perguntamos, qual é o lugar possível para um sujeito se inscrever enquanto autor do que chamamos "divulgação de ciência"? Que tipo de "mediação" se verifica aî?

Ao produzir materiais de divulgação na Revista "Ciência em Curso", temos refletido e trabalhado sobre a questão da "mediação", própria do discurso jornalístico, um discurso "sobre", conforme caracterizado por Mariani (1998, p. 61):

Do nosso ponto de vista, o discurso jornalístico, sobretudo na sua forma de reportagens, funciona como uma modalidade de discurso 'sobre', pois coloca o mundo como objeto. A imprensa não é o 'mundo', mas deve falar sobre este mundo, retratá-lo, torná-lo compreensível para os leitores. O cotidiano e a história, apresentados de modo fragmentado nas diversas seções de um jornal, ganham sentido ao serem 'conectados' interdiscursivamente a um já-lá dos assuntos em pauta. E essa interdiscursividade pode ser reconstruída através da análise dos processos parafrásticos presentes na cadeia intertextual que vai se construindo ao longo do tempo. É por aí a nossa compreensão do discurso jornalístico ter como característica atuar na institucionalização social dos sentidos.

O sujeito do discurso "sobre" está em posição de apontar para "o outro", objetalizando-o, ao falar "sobre" ele, e não com ele. Isso significa que qualquer dizer aí formulado está interpretado segundo os parâmetros dessa formação discursiva determinante do dizer jornalístico. Por esse motivo, a ciência (ou qualquer outro tema tratado) se converte em notícia, algo que precisamos saber como cidadãos, urbanos, etc. Há uma espécie de injunção a esses dizeres. A ciência aparece aí como "informação" científica, tal como formulada por Orlandi (2001), que devemos saber. Não se trata, portanto, de uma troca de conhecimento entre sujeitos, de uma interlocução, mas sim de um dizer unilateral da parte do jornalista, que cita o dizer do cientista, corroborando com isso seu próprio dizer.

GALLO - Contradições na divulgação... 
Procuramos minimizar essa "mediação" na divulgação científica que fazemos na Revista Ciência em Curso, principalmente na seção "feito a mão", na qual damos a voz ao entrevistado, procurando interferir o menos possível, de modo a deixar fluir o dizer do outro, participando de forma dialogada.

Sabemos que essa possibilidade está intimamente relacionada ao fato de que a divulgação que fazemos ocorre a partir da universidade. Portanto, não nos inscrevemos no discurso jornalístico quando fazemos divulgação. Decorrem de nossa inscrição no discurso acadêmico alguns fatores como, por exemplo, a extensão do tempo dedicado a cada número publicado; os interlocutores, que no caso da Revista são predominantemente alunos e professores universitários (enquanto leitores virtuais); e o fato de termos um procedimento de reflexão permanente e de ensino relacionado ao trabalho de divulgação. Esses fatores, nesse caso, são determinados pelo discurso acadêmico e acabam por determinar a produção.

Nesse sentido, temos privilegiado o processo de produção do conhecimento, tendo em vista a divulgação da ciência enquanto atividade de ensaio, constituída de erros, acertos, tateamentos e, mais do que "descobertas", procedimentos que visam à superação de obstáculos, à desmistificação de ideias preconcebidas, à abertura de caminhos e, principalmente, enquanto espaço de formulação de novas perguntas e novos desafios.

Ao destacarmos o processo na divulgação de ciência, pretende-se compreender o discurso da ciência através das suas condições de produção, através do resgate da sua historicidade. Busca-se com isso desfazer a evidência do fato científico entendido tanto como um resultado apenas, quanto como um processo infalível e absoluto, mostrando que existem acertos e erros que constituem o processo do qual o fato científico é resultado. Esse entendimento vai se refletir no discurso de divulgação que, como já dissemos, vai destacar o processo do fazer científico. Além disso, estamos interessados na compreensão do nosso próprio lugar enquanto divulgadores, ou seja, inscritos em um discurso acadêmico científico. (SIEBERT et alii, 2008) 
Assim, ao divulgar o conhecimento científico, temos procurado minimizar a mediação, experimentando, inclusive, outras formas de linguagem, como a linguagem do documentário. Segundo Flores, Lopes e Caetano, membros da equipe da revista:

Adotamos, por vezes, uma linguagem próxima do documentário, na qual, por exemplo, explicitamos a interação do entrevistador para com o entrevistado. A possibilidade de se produzir significados voláteis para o objeto é gerada pelo movimento natural do ambiente e de seus participantes (entrevistador e entrevistado). Dessa forma, torna-se imprescindível para nós, pesquisadores da Revista, participar dos vários processos científicos, pois isso nos permite contextualizar o próprio conhecimento científico que divulgamos, que sempre está aberto a novas possibilidades, que pode ser contestado, modificado e ressignificado [...] Percebemos, nessa experiência, que a ciência se faz não só de acertos e certezas, mas de dúvidas e tateamentos, e ainda, quanto é valioso o contexto em que se dá a pesquisa. (FLORES; LOPES; CAETANO, 2010, p. 91).

Seguem alguns exemplos desse tipo de produção:
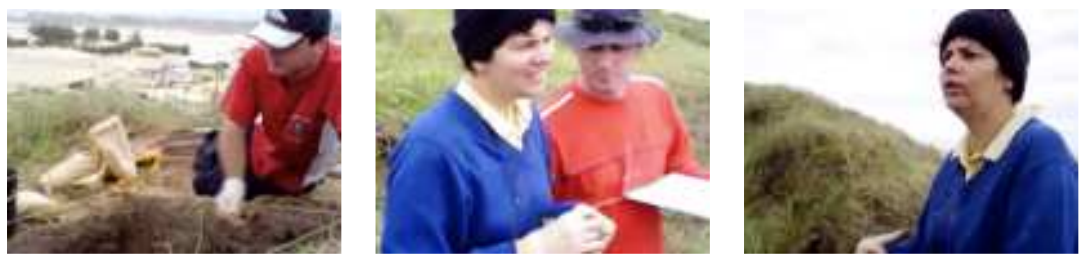

Figuras 1, 2 e 3: Patrimônio Histórico e Cultural

Fonte: Revista Ciência em Curso, v. 1, n. 3, abr.jun. 2006. Disponível em: http://www.cienciaemcurso.unisul.br/interna_capitulo.php?id_capitulo=20

Independente de uma preocupação com a qualidade desse vídeo, com uma técnica, que nessa fase do projeto ainda era muito precária, o que se pretendeu aí foi pegar justamente o momento em que o pesquisador não sabe, e que a ciência ainda não tem 
um resultado. Não se trata de uma notícia, mas de uma dúvida, uma pergunta: "agora deu um nó na cabeça". Porque apareceu um dado que não se encaixava nas premissas anteriores. Então, a partir desse momento, vai ser preciso entender o quanto esse dado pode modificar a teoria que estava posta. (GALLO, 2009, grifo nosso).

Sobre essa forma de divulgação que se evidencia, nesse caso, poderíamos ainda acrescentar que ela não produz uma notícia de ciência, enquanto produto de mídia, ao contrário:

É possível se perceber, aí, um processo científico. Como é que a pesquisa vai se dando, como é que as dúvidas vão aparecendo, e como é que as hipóteses vão constituindo respostas e vão gerando novas perguntas, enfim, exatamente o processo da ciência. (GALLO, 2009).

Esses materiais são feitos exclusivamente em audiovisual, sem o suporte escrito, de modo a mediar minimamente as falas, procurando não conter os sentidos com um texto verbal de divulgação, nem interpretar para os interlocutores o que eles estão assistindo.
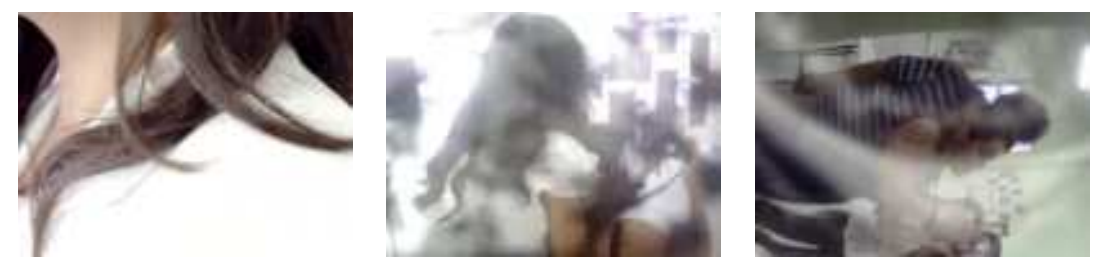

Figuras 4, 5 e 6: Projeto Hipermídia

Revista Ciência em Curso, v. 2, n. 4, jul./set. 2007. Disponível em: http://www.cienciaemcurso.unisul.br/interna_projeto.php?id_projeto $=18$ 
Segundo Flores, Lopes e Caetano (2010, p. 91), "Nessa produção audiovisual, o caráter documental e artístico se adéqua ao próprio ambiente de pesquisa. As várias possibilidades de significações geradas estão de acordo com o próprio ambiente".

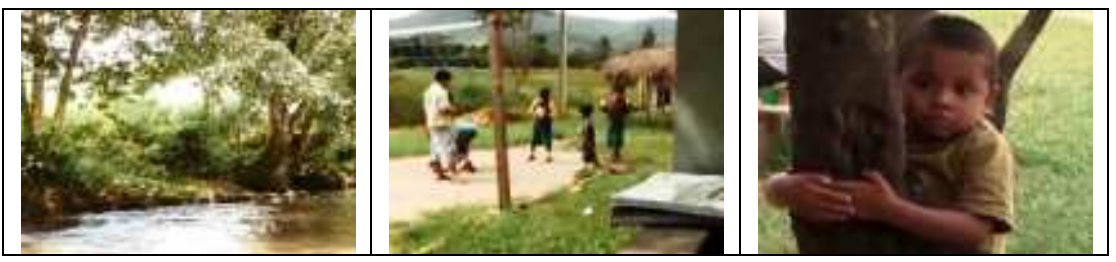

Figuras 7, 8 e 9: Revitalizando Cultura

Revista Ciência em Curso, V. 5, n. 3, abr./jun. 2010. Disponível em: http://www.cienciaemcurso.unisul.br/interna_capitulo.php?id_capitulo=176

A montagem foi feita para mostrar as mudanças de percepções que a própria equipe de produção tinha sobre a comunidade, tanto espacial, temporal e do ambiente como um todo. Utilizamos duas narrativas dentro do próprio vídeo, feitas justamente para mostrar o conflito entre dois tempos tão distintos. (FLORES; LOPES; CAETANO, 2010, p. 92).

Conforme Giovanella e Andrade (2010), pode-se perceber uma proximidade entre o modo de produzir divulgação de conhecimento e próprio modo de produção do que está sendo divulgado nesse trabalho:

Observamos no procedimento documental de certas produções (em vídeo ou em filme, lançadas em salas ou exibidas na TV e na web) duas grandes linhas, duas inclinações de base: aquelas que se apoiam fundamentalmente sobre a fala, e aquelas que se apoiam sobre o ato. Se observarmos, ainda, que a primeira tende a estruturar-se mais que a segunda e a segunda a ser mais discursiva que a primeira, é surpreendente a aliança, o acordo obtido entre discurso e materialidade nos vídeos do Feito a Mão: planos de 4 a 5 minutos que registram um processo desvelado na sua própria locução. Os resultados desse método surpreendem um pouco 
menos quando consideramos a natureza dessas produções: pequenos vídeos de curta duração, exibidos numa página dedicada ao estudo científico. A técnica utilizada nada mais é que a mais simples e a mais adequada: levando em conta a integridade do evento, do fato, a gravação é feita na maioria das vezes respeitando as unidades de tempo, ação e espaço das produções artesanais, respondendo, na prática mesmo do registro de imagens, perguntas elementares como "Onde isto pode ser feito?", "Quanto tempo leva?", "Que habilitações a pessoa precisa ter para a produção do material artesanal?”. Finalmente, e da mesma forma que o artesanato que privilegia o material do Feito a Mão assemelha-se sobremaneira às pequenas obras realizadas com esmero e consideração trazidas ao nosso conhecimento. A web transforma-se em ateliê. (2010, p. 128)

\section{A CONTRADIÇÃO ENTRE A C\&T E A CULTURA}

Dessa forma, o material produzido na seção "feito a mão" procura estabelecer, sempre que possível, um contraponto àquilo que vemos enquanto conhecimento científico divulgado.

Ao divulgar pesquisas em maricultura, por exemplo, a Revista "Ciência em Curso" mostrou os pesquisadores ${ }^{2}$ desenvolvendo as "sementes de ostras" e a "bombona" nos laboratórios da universidade, e os procedimentos e a tecnologia necessária para se conseguir essa produção

(http://www.cienciaemcurso.unisul.br/interna_projeto.php?id_projeto= 29).

Além disso, o número trouxe a "aplicação" da pesquisa em uma comunidade de maricultores, apresentando as mudanças produzidas no meio, decorrentes dessas pesquisas, e o dizer (satisfeito) dos maricultores entrevistados, além da fala de um pesquisador avaliando a perfeita sintonia, nesse caso, entre ensino, pesquisa e extensão:

2 Pesquisadores do LMM (Laboratório de Moluscos Marinhos), da UFSC e EPAGRE/SC. 
Na nossa área de trabalho, não tem como a gente fazer só ensino, ou só pesquisa, ou só extensão, o laboratório nosso é um laboratório que se caracteriza por ensino, pesquisa e extensão integrada, tudo voltado pra área de produção. Todo trabalho, aqui, é voltado pra área de produção, portanto todo trabalho é direcionado pra área de extensão, transferência de tecnologia. $E$ dentro disso a gente usa a parte de ensino e pesquisa também integrada, porque não dá pra gente só transferir tecnologia se não desenvolver essa tecnologia. Um projeto, por exemplo, que teve, recente, foi a gente transferir pro produtor sementes de ostras pequenas, de um milímetro, um milímetro e meio... não é comum a nível mundial. Aqui a gente também não fazia isso porque não tinha essa tecnologia. E a partir, por exemplo, de um projeto que foi parte de uma dissertação de mestrado mais um trabalho de conclusão de curso de um aluno, a gente desenvolveu, junto com um grupo de produtores, um sistema de flutuantes pra colocar essas sementes de ostras. Então essa foi uma ideia basicamente de um produtor, que precisava desenvolver isso, a gente trabalhou em conjunto, graduação, pós-graduação e o produtor. Esse sistema foi chamado de caixa flutuante (ou bombona), e hoje cerca de $80 \%$ dos produtores de ostra usam esse sistema pra sua produção... (Jaime F. Ferreira, Pesquisador do LMM, grifo nosso)
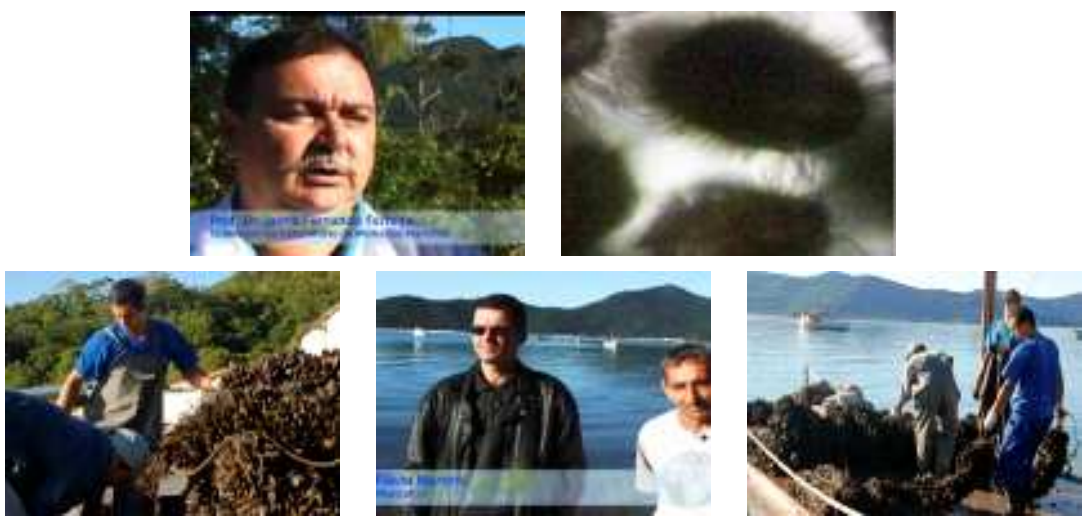

Figuras 10, 11, 12, 13 e 14: Maricultura em Santa Catarina II Fonte: Revista Ciência em Curso, v. 4, n. 4, jul./set. 2009 
“[...] (eu) conheci a filha dele, eu na época eu trabalhava como vendedor, (eu) trabalhava no super mercado também, e daí (eu) vi que a atividade era atividade boa, e (eu) migrei pra atividade... só que daí já tinha tecnologia diferente, né, a própria Epagre já trouxe, não fui eu o pioneiro, né, mas a Epagre trouxe a tecnologia... eu qdo comecei a criar, já (eu) comecei a criar na bombona... é onde eu brigo com ele até hj, que ele aprendeu a criar marisco depois que eu comecei... mas não é isso a questão... é que já tinha tecnologia da bombona... a gente, já que tava começando, eu resolvi começar na área já corretamente, saí daquele esquema de pau e bamboo e ir pra bombona..." (Flávio Martins, jovem maricultor, grifo nosso)

Ao analisarmos esses dizeres, concluímos dizendo que:

Se aproximarmos essa fala do jovem maricultor àquela do pesquisador, começaremos a notar uma certa mudança no fazer maricultura, que vem no bojo na nova tecnologia. Ou seja, a tecnologia, aqui, passa a ser preponderante enquanto elemento reordenador do fazer ("corretamente"). Não é mero instrumento entregue para um uso autônomo. O que organiza o fazer, agora, é a tecnologia, não mais as tradições. Por meio desses enunciados, observamos que o jovem maricultor constitui-se enquanto um sujeito que pensa sobre a "atividade" como fonte de renda, mas não se diz nesse fazer. (GALLO, 2011, grifo nosso).

A contradição, nesse caso, é explorada quando trazemos na seção "feito a mão" um maricultor que também se beneficia das "sementes" e da "bombona" produzidas na universidade, mas que, apesar disso, não deixa de identificar-se com o que faz, deixando marcar-se por essa identidade, assumindo a autoria do processo, a seu modo: 

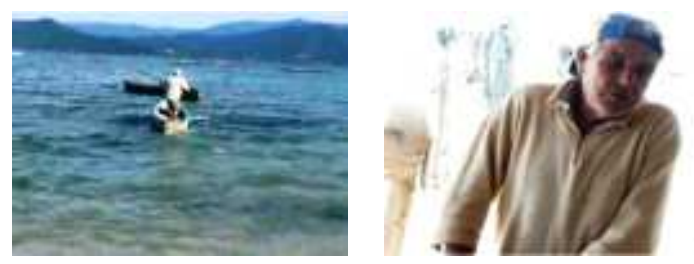

Figuras 15 e 16: Maricultura em Santa Catarina III

Fonte: Revista Ciência em Curso, v. 4, n.4, jul./set. 2009. Disponível em: http://feitoamao.unisul.br/index.php?option=com_hwdvideoshare\&task=view video\&Itemid=50\&video_id=41

“[...] (por isso também que o senhor lava sempre?) É... não é?... nós temos que trazer também toda, vez em quando, vez em quando, que ela "teje" pequena, que ela "teje" já adulta, mas nós temos que trazer "praqui" pra lavar e limpar ela porque senão ela morre, também...”

"[...] a universidade tem assim dado assim uma aula assim né, na entrada assim, agora tudo nós fizemos pela nossa mão porque nós já aprendemos tudo, nós já fizemos a lanterna, nós já compramos pano pro berçário, nós já fizemos o berçário, agora nós temos, vamos dizer, agora aqui nós "semo" professor..." (Sr. Valício, velho maricultor, grifo nosso)

$\mathrm{Na}$ análise desses dizeres contraditórios, pudemos formular que:

Se comparado ao sujeito do conhecimento artesanal, o sujeito da C\&T e Inovação é um sujeito que tem mais mobilidade, pois ele não "é" o que "é" em decorrência do que faz, mas em decorrência do que "pensa" sobre um determinado fazer. Assim, ele pode mudar de objeto de trabalho porque sua identidade não está vinculada a isso. E assim como a "atividade" é intercambiável, ele sujeito também o é. Já o sujeito que "faz a mão" tem sua identidade calcada nesse fazer, que não poderá ser feito por outro sujeito qualquer. Para tanto é necessária uma vida inteira de observação e experimentação, o que constitui uma condição única, territorializada. Esse sujeito não é intercambiável na sua comunidade. (GALLO; MARTINS, 2010, grifo nosso). 


\section{A CONTRADIÇÃO EM “CONTESTANDO O CONTESTADO”}

No âmbito de um projeto interinstitucional que estamos desenvolvendo com a Universidade do Contestado/SC, tivemos a oportunidade de produzir um número da revista tomando o conflito do Contestado como tema. Para tanto, fizemos entrevistas com sujeitos que mobilizam uma determinada memória do conflito, como vemos no caso aqui analisado e, de acordo com essa memória, nós temos dois discursos se contrapondo. As falas constroem, pela memória, dois discursos antagônicos. ${ }^{3}$

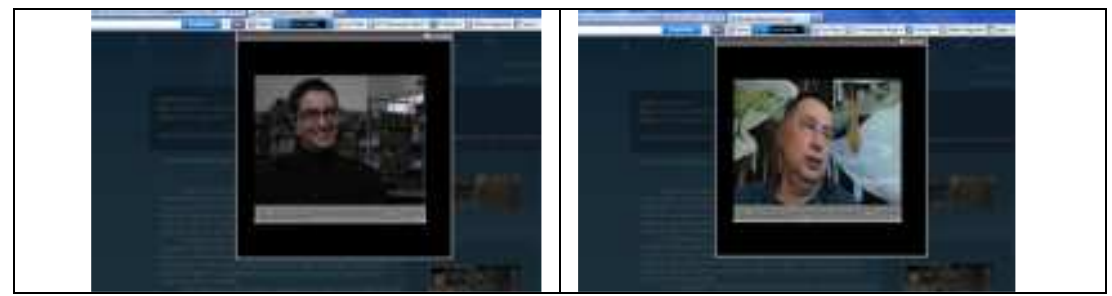

Figura 7: Filhos do Contestado

Fonte: Revista Ciência em Curso, v. 6, n. 1. out./dez. 2010. Disponível em: http://cienciaemcurso.unisul.br/interna_capitulo.php?id_capitulo=179

Tanto um entrevistado quanto o outro é considerado filho do CONTESTADO, na medida em que os dois têm ligação com essa história, e que é uma ligação não só de cidadania, mas também familiar: os dois tiveram membros de suas famílias ligados diretamente ao conflito do CONTESTADO. Porém, a forma material de ligação de cada uma das famílias ao acontecimento do CONTESTADO é bem diversa, adversária.

Nas falas deles é possível distinguir, a princípio, a memória de uma primeira discursividade, o discurso do Progresso. Esse discurso, no acontecimento "CONTESTADO", é assumido pelo governo, pelo Estado, pelo Exército, por coronéis que inclusive recebem a patente

${ }_{3}^{3}$ Segue em anexo a transcrição das entrevistas na íntegra. 
nesse momento por estarem ao lado do Exército, ajudando o Estado, e pela empresa que estava lá naquele momento, a Lumbert, trazendo essa ideia do progresso, da tecnologia. Portanto, o argumento dessa discursividade é a defesa do capital estrangeiro que seria colocado aqui na região. Todas essas posições-sujeito: o Estado, os coronéis, a Lumbert, estão encarnando essa discursividade.

Por outro lado, distingue-se a memória de uma outra discursividade, antagônica a essa, que é o discurso da resistência a todos esses sentidos. Esse é o discurso encarnado pelo sertanejo, pelo jagunço, e que tem no bojo a resistência à tecnologia, essa tecnologia que vinha junto do capital, e às mudanças econômicas que iriam se instalar na região.

Os sertanejos, os jagunços encarnam essa outra discursividade.

Nós podemos observar, nesse vídeo, essas duas discursividades sendo construídas na medida da reconstrução de uma memória mobilizada pela fala dos entrevistados. As duas falas reconstroem esse antagonismo que está presente nas duas diferentes discursividades. Tal é o antagonismo, no acontecimento mesmo do CONTESTADO, que uma discursividade não pôde conviver com a outra. Uma discursividade teve que eliminar a outra para poder existir, dada a impossibilidade de convivência desses dois sentidos. Tanto que a guerra se instaura justamente porque não há consenso possível, nesse caso. Não é possível admitir a permanência do outro sentido, quando se assume uma posição de um dos lados.

O que acontece na análise dessa situação hoje?

Assistindo a esse audiovisual que foi gravado agora, na contemporaneidade, distinguimos, aí, duas posições-sujeito, mas uma mesma discursividade. São dois entrevistados ocupando posições diferentes na forma de argumentos, mas ambos estão inscritos no mesmo discurso da contemporaneidade. Ambos estão falando de um CONTESTADO que é passado para ambos. Ambos se inscrevem em posições de um mesmo discurso, enquanto cidadãos. Ambos estão inscritos nesse discurso hegemônico, que estamos chamando de discurso da contemporaneidade. Esse discurso traz no bojo o sentido de democracia e de capitalismo. 
O que significa democracia, neste caso? Significa que as duas posições que em um determinado acontecimento são excludentes convivem hoje na mesma discursividade.

Assim, esse acontecimento CONTESTADO, que impedia a convivência de sentidos em contradição, hoje é relido, reinterpretado no bojo de uma discursividade outra, a da contemporaneidade, que torna perfeitamente possível a convivência desses sentidos no seu interior, simplesmente se diferenciando nos argumentos, mas coincidindo nos sentidos de capital, de tecnologia, de progresso.

Ambos os entrevistados significam o CONTESTADO como atração turística, por exemplo, que tem a ver com o capital, ambos se identificam com o sentido de progresso, de ciência e tecnologia, e ambos estão relacionados com o Estado, com o governo, no movimento de legitimação desse acontecimento que foi o CONTESTADO, nessa discursividade.

Podemos perceber que há muito mais aproximação do que distanciamento nessas duas posições. Uma das posições materializa um "filho do Contestado" que é historiador, cujo avô, no acontecimento do CONTESTADO, inscreve-se na posição de sertanejo; e a outra posição é sustentada pela diretora da Fundação Municipal de Cultura, cujo avô, no acontecimento do CONTESTADO, identifica-se como coronel.

Além dessas duas, nós poderíamos pensar em " $n$ ” outras posições de filhos do Contestado, todas convivendo hoje nessa grande discursividade que é a contemporaneidade, que, se por um lado promove o consenso, por outro lado dissolve a identidade familiar.

Esse funcionamento do discurso da contemporaneidade desloca as fronteiras ideológicas, e não é possível para nós, hoje, interpretar os acontecimentos com os mesmos gestos: interpretar nas condições históricas, ideológicas e sociais de hoje, os acontecimentos de ontem. O modo de constituição de identidade no acontecimento do Contestado é diferente do modo de constituição de identidade na contemporaneidade, na qual a forma de ser sujeito é muito mais fluida, muito mais "sem fronteiras", muito mais consensual e muito menos identitária, no sentido de uma identidade comunitária (talvez seja por isso que se fala tanto em comunidade, hoje, nomeando-a no momento em que ela está deixando 
de existir). No CONTESTADO, a categoria de comunidade é muito mais perceptível, a ponto de se morrer por ela.

O que estamos propondo aqui não é uma interpretação do CONTESTADO enquanto acontecimento social, mas sim de uma análise do gesto que interpretou e significou o CONTESTADO há cem anos, e do gesto possível para uma interpretação e significação do CONTESTADO, hoje. Lá como uma causa pela qual morrer, aqui como uma atração turística, por exemplo.

\section{ALGUMAS CONCLUSÕES}

No desenvolvimento do texto foi possível trazer alguns exemplos de materiais de divulgação de conhecimento, que materializam certas contradições que são constitutivas de nossa reflexão sobre divulgação científica. Procurarei nesta seção enunciá-las e formular algo (conclusivo?) sobre elas.

\section{(a) Primeira contradição: jornalismo científico e divulgação científica - a questão da mediação}

Temos nos contraposto a uma forma de divulgação científica praticada pelo jornalismo científico tanto da mídia impressa, especializada ou não, quanto de outras mídias. Nessa forma de divulgação o sujeito, na posição de divulgador, inscreve-se predominantemente no discurso jornalístico que, como vimos, caracteriza-se como um discurso "sobre". Isso delimita a forma da divulgação que, apesar do atravessamento do discurso da ciência, é a memória própria da mídia e do discurso jornalístico e não a memória do discurso científico que é mobilizada como pré-construído desse dizer.

De tal modo, produz-se uma memória da ciência, que se constitui pela mídia e não pela própria ciência. O resultado disso é um simulacro de ciência exposto à população leiga, simulacro este que surge como efeito da não-explicitação das condições de produção da pesquisa científica. Para o público leigo, a ciência se produz de forma descontextualizada e descontínua. (MARTINS; MORELLO; GALLO, 2008, p. 123) 
Essa é a primeira contradição que colocamos em evidência com o nosso trabalho de divulgação: a contradição existente entre divulgar ciência e fazer jornalismo. O que estabelecemos como ponto de diferenciação dessas duas posições discursivas é justamente como cada uma incorpora o gesto de mediar: no caso do jornalismo, como vimos, trata-se de um gesto que objetaliza o outro; enquanto que na divulgação que não se inscreve no discurso jornalístico, trata-se de um gesto que pode dar lugar a um dizer outro (de sujeitos interlocutores), mesmo considerando que esse dizer é sobredeterminado por uma "edição".

Essa contradição leva a uma outra, que é decorrente da primeira: a de se priorizar o produto (notícia), quando se procura esclarecer sobre o processo. Nesses casos, temos visto o que chamamos de um atravessamento do discurso pedagógico, materializado na forma de box ou de "infográficos" e outras estratégias de ilustração, na tentativa de “instruir", conforme aponta Lucas (2011, p. 80-81):

A ciência é apresentada enquanto modo de produção. E como funciona essa formação discursiva dentro da Divulgação Científica? Como formação discursiva em funcionamento ligado ao pedagógico, que significa uma questão de ensinar o modo de funcionamento da ciência e de como ela chega a determinados resultados. Na relação do Discurso Pedagógico com o Discurso Jornalístico se chega a uma relação do Discurso Científico. Nesses enunciados que são como janelas, que são a materialização do Discurso de Divulgação Científica, é possível perceber de um lugar mais próximo da ciência, como ela se constitui, se enquanto uma ciência que tem uma característica humanitária e social ou se enquanto uma ciência que está toda sustentada pela tecnologia. Isso só pode ser visto a partir do lugar em que a ciência se enuncia, mesmo que do modo pedagógico. Há um lugar aí de enunciação que se articula com o Jornalismo Científico para falar a ciência do lugar da ciência, ou pelo menos produzindo esse efeito de que é o lugar da ciência. 


\section{(b) Segunda contradição: conhecimento científico e conhecimento cultural}

Uma segunda contradição importante que a reflexão sobre o discurso da divulgação científica nos permitiu formular refere-se ao que vemos ser, hoje, uma predominância nos discursos oficiais (ministérios, secretaria, fundações de apoio à pesquisa, universidades, etc.), que é a injunção da ciência ao que se denomina C\&T e Inovação. Desse modo, as ciências sociais e humanas vão perdendo espaço, prestígio e recursos. Mas a consequência mais importante disso é o "esquecimento" - nos termos propostos por Pêcheux (1994), enquanto região de sentido apagada pela ideologia, zona do impensado - daquilo que essa forma de conhecimento silencia: justamente os saberes processuais, tradicionais, relativos às comunidades da base social. Todos os sentidos de ciência, na contemporaneidade, parecem convergir para a tão propagada "produção de riqueza" e autossuficiência. O que temos apontado como contradição é que esse tipo de desenvolvimento científico e tecnológico, justificado por uma certa "qualidade de vida", coloca-se em detrimento da "qualidade de vida" já conquistada de modo assistemático, baseada em tecnologias sociais. Ou seja, em uma economia globalizada, os pequenos produtores, os produtores regionais, cuja produção se sustenta em um conhecimento cultural tradicional (muitas vezes familiar), têm tido cada vez mais dificuldade de fazer sentido, assim como a comunidade do seu entorno.

Se comparado ao sujeito do conhecimento artesanal, o sujeito da C\&T e Inovação é um sujeito que tem mais mobilidade, pois ele não "ê" o que "é" em decorrência do que faz no seu "território", mas em decorrência do que "pensa" sobre um determinado fazer, onde quer que esteja. Assim, ele pode mudar de objeto de trabalho porque sua identidade não está vinculada a isso. E assim como a "atividade" é intercambiável, ele sujeito também o é. Já o sujeito que "faz a mão", esse tem sua identidade calcada no fazer, o que não poderá ser feito por outro sujeito qualquer, em qualquer lugar. Para tanto é necessária uma vida inteira de observação e experimentação, o que constitui uma condição única, territorializada. Esse sujeito não é intercambiável na sua comunidade. (GALLO, 2011). 


\section{(c) Terceira contradição: discurso da contemporaneidade e memória}

A terceira contradição que queremos registrar aqui como decorrente das análises que temos feito de textos do discurso de divulgação de conhecimento é relativa a uma certa forma de "esquecimento" daquilo que constitui identidade, de modo que determinados sentidos contraditórios, que poderiam aparecer como materialização de uma posição política, aparecem apenas como argumento retórico contraditório.

Temos relacionado esse funcionamento ao discurso da contemporaneidade, cuja forma-histórica é o capitalismo. Esse discurso é hegemônico, mas não é único nem homogêneo, e temos procurado trabalhar na compreensão de suas contradições por meio de um trabalho sobre a memória.

Finalizando, gostaríamos de salientar que tanto a Revista "Ciência em Curso" quanto o projeto "feito a mão" são produções de divulgação de conhecimento, mas ao mesmo tempo constituem-se em laboratório de análises discursivas, por meio do que refletimos sobre as questões relacionadas à produção do conhecimento na nossa sociedade e sobre o modo como este é significado no seio das relações de poder, que se materializam em contradições, como procuramos mostrar.

\section{REFERÊNCIAS}

FLORES, G. B.; LOPES, A. C.; CAETANO, R. M. A Revista Ciência em Curso e a divulgação científica do patrimônio. In: NECKEL, N.; MILANI, M. L. (Orgs.). Cultura: faces do desenvolvimento. Blumenau: Nova Letra, 2010. p. 87-96.

GALLO, S. L. RUA [online], v. 2, n. 15, 2009. Disponível em:

$<$ http://www.labeurb.unicamp.br/rua/pages/home/ capaArtigo.rua?id=73 www.cienciaemcurso.unisul.br>. Acesso em: set. 2011.

A Ciência da Linguagem e a tecnologia. Revista da Abralin. Curitiba, 2011. (no prelo). 
; MARTINS, M. F. Ciência em Curso \& feito a mão. In: NECKEL, N.; MILANI, M. L. (Orgs.). Cultura: faces do desenvolvimento. Blumenau: Nova Letra, 2010. p. 133-140.

GIOVANELLA, L. F.; ANDRADE, B. Feito a mão e sabedoria popular. In: NECKEL, N.; MILANI, M. L. (Orgs.). Cultura: faces do desenvolvimento. Blumenau: Nova Letra, 2010. p. 125-131.

LUCAS, J. A. Análise do discurso de divulgação científica na imprensa catarinense. 2011. 94f. Dissertação (Mestrado em Ciências da Linguagem) Programa de Pós-graduação em Ciências da Linguagem, Universidade do Sul de Santa Catarina, Palhoça, 2011.

MARIANI, B. O PCB e a imprensa: os comunistas no imaginário dos jornais (1922-1989). Rio de Janeiro, RJ: Revan; Campinas, SP: Editora Unicamp, 1998.

MARTINS, M. F.; MORELLO, R.; GALLO, S. L. Linguagens, ciências e tecnologias na formulação do conhecimento. In: Braga, S.; REIS, M. S. dos; MORITZ, M. E.; RAUEN, F. J. (Orgs.). Ciências da Linguagem: avaliando o percurso, abrindo caminhos. Blumenau: Nova Letra, 2008. Coleção Linguagens. p. 115-128.

ORLANDI, E. Divulgação Científica e efeito-leitor: uma política social urbana. In: GUIMARAES, E. (Org.). Produção e circulação do conhecimento. Vol. I. Campinas: Ed. Pontes, 2001. p. 21-30.

PÊCHEUX, M. Ler o arquivo hoje. In: ORLANDI, E. (Org.). Gestos de leitura. Campinas: Ed. da Unicamp, 1994. p. 55-66.

SIEBERT, S.; FLORES, G. B.; MARTINS, M. F.; GALLO, S. L. A ciência enquanto processo: um caso de divulgação. Trabalho apresentado no IV Congresso Internacional de Comunicação, Cultura e Mídia - coMcult, no Centro Universitário Belas Artes de São Paulo, novembro de 2008.

\section{ANEXO: FILHOS DO CONTESTADO 4}

(Sons: Canto de pássaros, Maria Fumaça, apito de trem, motores, tráfego)

Solange Gallo (SG): Muito bem...

${ }^{4}$ Agradeço à doutoranda do PPGCL Regina Milleo pelo trabalho de transcrição.

GALLO - Contradições na divulgação... 
SG: O Fernando Tokarski é um polaco, né, e que nos disse que a família dele ficou do lado dos sertanejos na Guerra... Ah, como que foi para sua família, Viviane, que que você tem de registro dessa, desse momento, dessa experiência familiar?

SG: Essas comunidades como a da sua família, né, de polacos e outras que havia aqui, ah, tomaram posição nessa Guerra?

Fernando Tokarski (FT): Ah, sim, até, eu tenho um trabalho, não sei se professora conhece o Professor Paulo Pinheiro Machado?

SG: Sim.

FT: Então, o Paulo é meu amigo, e até eu escrevi um artigo para um livro que ele organizou, é, um livro claro feito a várias mãos, né, eu analiso a questão étnica na Guerra do Contestado, porque normalmente se fala que a Guerra do Contestado foi uma Guerra sertaneja.

SG: Isso...

FT: É, mas afinal, quem era esse sertanejo que participa da Guerra

SG: Pois é... né...

FT: Era um sertanejo porque morava no sertão, óbvio, mas qual a etnia desse sertanejo, né, e por uma razão muito óbvia eu analisei a participação dos polacos na Guerra do Contestado...

SG: Claro... Hum... Hum... Por que será? (risos)

FT: Por que será? (risos) Sei... Eu sempre falo isso... né...(risos)

FT: Então, houve na Guerra do Contestado, claro, além do nosso caboclo, claro, que era a grande maioria que participa da Guerra tanto do lado revoltoso como eu chamo e do lado das forças legais, há participação de germânicos, principalmente, de polacos, ucranianos, né, e até italianos, né, nesse conflito...

SG: E de que lado os polacos estavam?

FT: A maioria ficou do lado revoltoso, do lado da população civil, claro, a maioria, mas há também alguns que lutam ao lado das forças legais, principalmente, daquilo que nós chamamos de vaqueanos que eram civis que eram mantidos por coronéis ou pelo próprio exército, né, e que eram os guias durante a Guerra 
do Contestado e que até recebiam soldos, também, né, e lutavam ao lado das forças militares, né, há muito... Mas, claro, a maioria ficou do lado...

SG: Ah, eles ganhavam!

FT: Ganhavam para isso... Sim... Eles ganhavam... Sim... Ah, não sei qual é o grau de parentesco agora da Viviane, esqueci... Leocádio Pacheco que era um ancestral dela, ele tinha um bando armado, né, e pago por ele, sustentado por ele, isso era muito comum naquela época.

Viviane Bueno (VB): A minha família teve um envolvimento muito grande durante a Guerra do Contestado, é, do lado das tropas federalistas, do lado dos coronéis, sendo meu bisavô um coronel, né, não de título, é de patente, do exército, mas denominado coronel por ter muitas terras, coronel Leocádio Pacheco dos Santos Lima é que formou um piquete de vaqueanos aonde lutou no reduto Santa Maria contra os caboclos, e foi morto durante o combate no reduto Santa Maria, onde foi o último reduto da Guerra do Contestado. Hoje, é cidade de Timbó Grande, né, Santa Catarina, e também toda família teve em função da Guerra do Contestado fornecendo gado, alimento para as tropas do exército, após a morte do coronel, a viúva também continuou fornecendo, e recebia do governo federal, recibos do que levava, o gado, o alimento que até hoje a família tem os recibos que nunca recebeu é o que era mandado para manter as tropas durante a Guerra, então, sempre foi debatido dentro da família a Guerra do Contestado dando a continuidade da participação da família também durante a Guerra, isso são registros, são marcas, são históricos, são fotografias, são documentos que ficaram dentro da nossa família registrando a importância da Guerra do Contestado.

SG: A população que estava envolvida com isto e que de alguma forma ainda está hoje respondendo por esta cultura, como você disse, né...

FT: $\operatorname{Sim} . .$.

SG: Nós temos colegas que tiveram seus vós, bisavós, do lado legal do conflito, hã, como que fica, ah, você que fez o livro sobre isto e que entrevistou essas pessoas e que compõe esta memória, né, como que fica a relação ética, né, com, com, de ter assumido 
esta posição, que era uma posição... De terem assumido a posição de irem violentamente contra as famílias dos colonos, enfim, do sertanejo, né...

FT: Bom, é, vejo que antes de mais nada sempre está a ideia da defesa do capital, isso justifica tudo, né, então, se, é o que o exercito também fez aqui, né, ao invés de vir aqui e defender a população simples, espoliada de suas terras, de seus recursos econômicos, né, despojada, aliás, das terras já falei... o exército vem para cá principalmente na defesa do capital internacional que era a própria estrada de ferro e a Lambert, então, isso justificou tudo, e como toda guerra tem uma justificativa econômica a do Contestado não foi diferente, então, isso para mim ainda é plenamente justificável do ponto de vista dessa herança cultural que está aí, né, porque o sertanejo então o pessoal que fez a Guerra do Contestado estava de certa forma indo de encontro a esta chegada da tecnologia, das mudanças econômicas, e justificou-se plenamente então esta matança este genocídio regional que aconteceu por aqui.

SG: Viviane, parece natural a posição que o seu avô assumiu na guerra, né, devido ao fato de ele ter que defender as suas próprias terras. Como que você vê isso, nas condições de hoje, nós temos, hoje, latifundiários e sem terra e pode estabelecer um paralelo com esta situação, ou seja, o governo continua protegendo e se associando aos latifundiários em detrimento dos sem terra que parece ser análogo ao que aconteceu na Guerra do Contestado. Como que você vê esta situação? Como que você se posiciona em relação a isto?

VB: Eu acho que existe no Brasil muitas terras improdutivas, mas tem que ter uma política muito é melhor para os assentamentos e para este trabalho da retirada destas terras improdutivas dos proprietários para ser repassada para os sem terra, tem que melhorar muito esta política por que hoje ela já está virando quase um trabalho profissional, de pessoas que vão, recebem as terras, vendem as terras e passam para outro acampamento. Eu acho importante estas terras que são improdutivas, trabalhar uma área de divisão, mas que a pessoa trabalhe e pague por esta terra, não que ela vá ganhando e vá passando para outros assentamentos. Então, esta política tem que ser melhorada muito, é como aconteceu no passado os caboclos eram os sem terra de 
hoje, né, eram os sem terra de hoje, e os coronéis como ainda hoje os proprietários de terra têm combate contra os sem terra pela invasão das terras, não há uma mortandade tão grande como houve naquela época, como agora acontece mais, é a mesma coisa em épocas diferentes.

SG: $\mathrm{E}$ essas figuras aqui?

VB: Acho que ele quis colocar aqui o monge de um lado e os coronéis do outro lado, a figura o caso do toco de jaguatirica, ali, no final do fogo das velas... É...

FT: Ah, é... Tá... Eu não estava vendo isto, não...

VB: Também aqui, através do desenho dessa árvore ou dragão...

FT: Hum...

VB: ...que pode ser interpretado e aqui um instrumento utilizado pelo exército...

FT: Ah, sim, uma arma... Sim...

VB: Isso, uma arma dos dois lados a figura dele no meio e no lado aqui o coronel e o confronto entre o monge e no meio este abismo pode-se interpretar o fogo como as almas que ficaram no chão e o tom do vermelho é sempre o sangue.

FT: Sangue... Tá...

(Som Maria fumaça)

Recebido em 20/10/11. Aprovado em 13/12/11.

Title: Contradictions in the divulgation of scientific and cultural knowledge

Author: Solange Leda Gallo

Abstract: Here we have a reflection on the work that has been developed for some years by one of the research groups inscribed in the "Text and Discourse" research line at PPGCL, Unisul. This work has taken form in the many scientific publications from all group members and two productions in the field of knowledge divulgation: the journal "Ciência em Curso" (www.cienciaemcurso.unisul.br) and the project "Feito a Mão" (wnw.feitoamao.unisul.br), both digital productions. Here we discuss the contradictions in the production of knowledge and its forms of broadcasingt, in accordance with previously developed analyses. These analyses phrase the questions regarding the mediation of scientific journalism and science divulgation; the issues of scientific knowledge and cultural knowledge; the question of science and its relationship with Science \& Technology, and the question of contemporary discourse and the discourse of memory.

Keywords: Discourse Analysis. Scientific and cultural knowledge divulgation. Contradiction. Memory.

GALLO - Contradições na divulgação... 
Título: Contradicctiones em la divulgación de conocimiento científico y cultural

Autor: Solange Leda Gallo

Resumen: Aqui hacemos una reflexión sobre el trabajo que viene siendo desarrollado hace algunos años en el ámbito de uno de los grupos de pesquisa inscripto en la línea de pesquisa de "Texto y Discurso" del Programa de Posgraduación en Ciencias del Lenguaje de la Unisul. Ese trabajo se materializa en varias publicaciones cientificas de todo grupo y en dos producciones digitales de divulgación de conocimiento, la Revista "Ciencia en Curso" (wnw.cienciaemcurso.unisul.br) y el Proyecto "becho a mano" (wnw.feitoamao.unisul.br). Discutimos aqui las contradicciones que están en la base de la producción de conocimiento y de sus formas de circulación de acuerdo con resultados de análisis ya desarrolladas. Esos análisis recortan la cuestión de la mediación en El periodismo científico y en la divulgación científica, la cuestión del conocimiento cientifico y del conocimiento cultural, la cuestión de la ciencia en relación a la C@T; y la cuestión del discurso de la contemporaneidady de la memoria.

Palabras-clave: Análisis de discurso. Divulgación de conocimiento cientifico y cultural. Contradicción. Memoria. 